\title{
Atypical: Life with Asperger's in 20 1/3 chapters
}

\author{
Author: Jesse A. Saperstein
}

Published by: The Penguin Group, 2010, 240 pages

Reviewed by: Sergio E. Madrid, Family Outreach and Aggie Welcome \& Orientation, New Mexico State University

This autobiographic material from Jesse Saperstein is a contemporary masterpiece by its own right. Although it is non-fiction, this narrative is very entertaining reading. It has everything a good novel must have without being one: a powerful human story, drama, laughter, a lot of strangely funny passages, and real-life happenings. The author really nails a wonderful complete piece. Moreover, it is surprisingly funny and easy to follow, a perfect read for new college students coming to increasingly diverse campuses or for class discussions. I agree with Temple Grandin when she said the author's writing is brilliant and creative.

Despite the title of the book, Atypical, there is no relation with the popular Rashid's Netflix show with the same name. Both pieces are breathtaking; Saperstein's style is both honest and passionate, and the readers will find themselves easily captivated by his smart fluent writing, which will keep them connected with his narrative. The most well-known signs of Asperger's syndrome, such as social clumsiness, lack of clarity within non-verbal communications, apparent emotional inaccessibility, rituals, routine, and limited range of interest, are presented within an honest and clear framework. Saperstein presents an image far different from picturesque pop culture stereotypes like Hollywood's bizarre math 
geniuses or prime time sitcoms' extraordinary silly outcasts.

With this narrative, Saperstein brings to light the conversations we should be having as an inclusive society. This book gives voice to those individuals who conventionally are left just one inch outside society because the public commonly perceives their mild form of autism not as a disability, but rather as a character lack, intentional impoliteness, or rude selfishness. Having this first-hand perspective from an individual with Asperger's is an eye-opening experience, tearing down the barriers and prejudices of traditional beliefs about this syndrome. Indeed, by raising his voice about living with Asperger's, Saperstein empowers along with him a historically underserved group in the community. This book is almost like a poem, lyrically reciting about embracing diversity, the miracle of inclusion, and us all getting along together as a society by being openminded and accepting. In sum, Atypical: Life with Asperger's in 20 1/3 Chapters is about us all building a more fair society for all.

Every chapter is a dynamic honest perspective from the author; however, I feel some chapters are specifically relevant to the current educational climate. Let us take Chapter 5: The Inability to Let Go as an example, where Saperstein reflects on the ballast of bullying. As a result, a raw description of the phenomena from the bullied individual's perspective emerges, informing the paradox between his human need of being accepted and his social ineptitude that unavoidably separated him from the crowd. Saperstein beautifully described this paradox: "I morbidly craved for negative attention because it was more gratifying than the alternative: being ignored" (Saperstein, 2010, p. 5). Therefore, this negative attention usually ended in brutally honest responses both verbal and physical. In sum, student affairs professionals should consider this reading for a better understanding of both angles: the victims and the perpetrators of bullying. This narrative brings awareness to the idea that most of the time it is just a huge misunderstanding.

Professionals in the student services and campus life field deal with conflict on a daily basis. Nevertheless, the tension between neurotypicals (e.g. individuals not affected by autism spectrum disorder) and atypicals (e.g. those framed within the autism spectrum) is deeply rooted in our 
collective failure to understand each other. Neurotypical people appear in the atypical mind as a myriad of hidden signals and unintelligible mind games, and the atypical mind appears to the neurotypical individual as a character flaw to be corrected. In a broader sense, this sort of misunderstanding is true not only for atypical individuals but for many incoming freshmen dealing with the college setting for the first time.

This book offers us the valuable possibility to understand each other (i.e. neurotypical and atypical individuals). Many readers are likely aware of the exponential growth of the atypical population not only in elementary or secondary schools, but in higher education as well. There is a critical need for literature, practices, and policies that can educate us on such an important and current matter. Moreover, this is a perfect reading to incorporate into new student programming. This process of sensibilization is essential for everyone involved in higher education programming, including orientation specialists, faculty, orientation leaders, resident assistants, dinner services, and campus activities organizers, and I honestly believe this book achieves that goal and beyond.

This book resonated with me on many different levels, as an individual, as a professional in the special education field, as an orientation specialist, but especially as a human experiencing Asperger's myself. I think it is important to applaud Saperstein's effort in putting himself out there, and how by doing so he has provided all of us with a voice. This book gives the public a taste of how it is living with autism while breaking down prejudices and stereotypes and closing the natural gap between neurotypical and atypical individuals. Thus, the moral of this book, if any, could be in the author's own words: "we are two opposing species drowning in our respective egos and judging each other on misunderstandings. No side is better or worse than the other. Just different..." (p. 4). The embedded message could be that we must learn from each other because we need to get along. All of us can become closer as part of something bigger than us, the one and only human race.

This book is so approachable and significant that I recommend it for many different groups - for general student readings, students studying education, or professional staff and student assistants in the student 
affairs field. It also could be used by university groups who provide opportunities for inclusion and diversity (e.g., Chicano programs, Black programs, LGBTQ+, and others). There is something for everyone in this narrative. This could even serve as a textbook or reading in certain undergraduate courses (e.g., English, College 101, Writing). Having this game-changing perspective from an individual with Asperger's promotes discussion opportunities and brings to light the conversations we should have been having on our campuses, regardless of their size or location; we all should be heading towards a more socially just and inclusive society. 